\title{
Clinical Indicators for Differential Diagnosis of Acute Lower Abdominal Pain in Women of Reproductive Age
}

\author{
Kijja Jearwattanakanok ${ }^{\mathrm{a}}$, Sirikan Yamada ${ }^{\mathrm{b}}$, Watcharin Suntornlimsiric ${ }^{\mathrm{c}}$, Waratsuda Smuthtai ${ }^{\mathrm{d}}$, \\ Jayanton Patumanond ${ }^{\mathrm{e}, \mathrm{f}}$
}

\begin{abstract}
Background: Acute lower abdominal pain in women of reproductive age is a challenging condition for clinical diagnosis. Computerized tomography yields high accuracy, but may not be cost-effective in low-middle income countries. Selective diagnostic approach based on clinical findings may be more appropriate.
\end{abstract}

Methods: Medical record review was performed on patients aging between 15 - 50 years who admitted to the surgical department or obstetrics and gynecology (OB-GYN) unit because of acute lower abdominal pain during January to December 2008. Patients were eventually categorized into appendicitis, OB-GYN conditions, or non-specific abdominal pain (NSAP). Clinical indicators were studied for diagnostic values using polytomous logistic regression applied to likelihood ratio for positive test $(\mathrm{LR}+)$ and confidence interval (CI).

Results: Anorexia, nausea and vomiting, shifting of abdominal pain decreased the likelihood of OB-GYN conditions. Diarrhea increased the likelihood of NSAP. Right lower quadrant tenderness increased the likelihood of appendicitis but decreased the likelihood of OB-GYN conditions. Left lower quadrant tenderness decreased the likelihood of appendicitis but increased the likelihood of OB-GYN. Guarding or rebound tenderness increased the likeli-

Manuscript accepted for publication May 24, 2013

${ }^{a}$ Department of Surgery, Nakornping Hospital, Chiang Mai, Thailand

${ }^{b}$ Division of Gastrointestinal Surgery and Endoscopy, Department of Surgery Faculty of Medicine at Chiang Mai University, Chiang Mai, Thailand

'Department of Obstetrics and Gynecology, Nakornping Hospital, Chiang Mai, Thailand

${ }^{\mathrm{d}}$ Department of Emergency Medicine, Nakornping Hospital, Chiang Mai, Thailand

${ }^{\mathrm{e}}$ Clinical Epidemiology and Clinical Statistics Unit, Faculty of Medicine at Chiang Mai University, Chiang Mai, Thailand

${ }^{\mathrm{f}}$ Corresponding author: Jayanton Patumanond, Faculty of Medicine at

Chiang Mai University, Chiang Mai, 50200, Thailand.

Email: jkijja@gmail.com

doi: http://dx.doi.org/10.4021/jcs179w hood of appendicitis but reduced the likelihood of NSAP. Leucocytosis (white blood cell count $\geq 10,000$ ) increased the likelihood of appendicitis but reduced the likelihood of OB-GYN and NSAP. Neutrophil $\geq 75 \%$ increased the likelihood of OB-GYN but decreased the likelihood of NSAP. Pregnancy reduced the likelihood of appendicitis and increased the likelihood of OB-GYN.

Conclusion: Gastrointestinal symptoms, sites of abdominal tenderness, guarding or rebound tenderness, leucocytosis, neutrophil $\geq$ $75 \%$ and pregnancy are clinical indicators that may help differentiating appendicitis, common OB-GYN conditions, or NSAP in acute lower abdominal pain in women of reproductive age.

Keywords: Lower abdominal pain; Pelvic pain; Appendicitis; Ectopic pregnancy; Ovarian cyst; Non-specific abdominal pain; Likelihood ratio; Polytomous logistic regression

\section{Introduction}

Abdominal pain is a common chief complaint of patient at emergency departments. Diagnosis of abdominal pain, especially for lower abdominal pain in women of reproductive age, is challenging. Appendicitis, pelvic inflammatory disease (PID), ectopic pregnancy, and complicated ovarian cyst are common conditions that cause acute lower abdominal pain in childbearing age women [1].

As all common diagnoses of acute lower abdominal pain are emergency conditions, timely diagnosis and management are important. Physical examination alone, for example, pelvic examination has low accuracy in diagnosing lower abdominal pain [2]. Diagnostic investigations such as trans-vaginal ultrasound, computerized tomography (CT), magnetic resonance imaging (MRI), and laparoscopy are used with more accuracy [3-8]. These sophisticated investigations, however, require time, resources and medical specialties. The universal uses of these special investigations may not be available in every hospital, and transferring patients for investigation may result in delayed treatment. In appendicitis, for example, a study showed that more accurate diagnosis was associated with higher rate of ruptured appendicitis [9]. In low-middle income countries special investiga- 
Table 1. Demographic Characteristic and Clinical Findings of Patients With Appendicitis, Obstetrics-Gynecological Conditions (OB-GYN), and Non-Specific Abdominal Pain (NSAP)

\begin{tabular}{|c|c|c|c|c|c|c|c|}
\hline \multirow{2}{*}{ Characteristics } & \multicolumn{2}{|c|}{$\begin{array}{l}\text { Appendicitis } \\
(n=382)\end{array}$} & \multicolumn{2}{|l|}{$\begin{array}{l}\text { OB-GYN } \\
(\mathbf{n}=\mathbf{9 7})\end{array}$} & \multicolumn{2}{|l|}{$\begin{array}{l}\text { NSAP } \\
(n=63)\end{array}$} & \multirow{2}{*}{ P-value } \\
\hline & $\mathbf{n}$ & $\%$ & $\mathbf{n}$ & $\%$ & $\mathbf{n}$ & $\%$ & \\
\hline \multicolumn{8}{|l|}{ Age (yr) } \\
\hline$>25$ & 169 & 44.2 & 41 & 42.3 & 27 & 42.9 & \\
\hline Mean (SD) & 30.1 & $(11.3)$ & 28.9 & $(8.8)$ & 29.9 & $(10.4)$ & $0.937 *$ \\
\hline Single & 193 & 50.8 & 49 & 51.0 & 33 & 53.2 & 0.943 \\
\hline \multicolumn{8}{|l|}{ Duration of pain (hr) } \\
\hline$>24$ & 94 & 24.6 & 39 & 40.2 & 21 & 33.3 & \\
\hline Mean (SD) & 31.2 & $(32.0)$ & 52.4 & $(65.9)$ & 34.9 & $(37.4)$ & $0.413^{*}$ \\
\hline Shifting of pain & 142 & 31.2 & 6 & 6.2 & 11 & 17.5 & $<0.001$ \\
\hline Anorexia & 43 & 11.3 & 2 & 2.1 & 6 & 9.5 & 0.010 \\
\hline Nausea and vomiting & 200 & 52.4 & 15 & 15.5 & 20 & 31.8 & $<0.001$ \\
\hline Abnormal vaginal bleeding & 1 & 0.1 & 28 & 28.9 & 2 & 3.2 & $<0.001$ \\
\hline Diarrhea & 29 & 7.6 & 4 & 4.1 & 13 & 20.6 & 0.002 \\
\hline Temperature $\geq 37.5^{\circ} \mathrm{C}$ & 124 & 33.3 & 14 & 14.6 & 12 & 19.4 & $<0.001$ \\
\hline Pulse rate $(/ \mathrm{min})$ & $(n=374)$ & & $(\mathrm{n}=97)$ & & $(\mathrm{n}=62)$ & & \\
\hline Tachycardia $(\geq 100)$ & 115 & 30.6 & 24 & 24.7 & 10 & 16.3 & \\
\hline Mean (SD) & 90.8 & $(15.5)$ & 88.0 & $(17.4)$ & 85.2 & $(17.0)$ & 0.021 \\
\hline Systolic blood pressure $(\mathrm{mmHg})$ & $(\mathrm{n}=374)$ & & $(\mathrm{n}=97)$ & & $(\mathrm{n}=61)$ & & \\
\hline Hypotension $(<90)$ & 4 & 1.1 & 12 & 12.4 & 1 & 1.6 & \\
\hline Mean (SD) & 121.8 & $(15.9)$ & 112.4 & $(18.5)$ & 117.9 & $(14.3)$ & $<0.001$ \\
\hline RLQ tender & 374 & 97.9 & 71 & 73.2 & 53 & 84.1 & $<0.001$ \\
\hline LLQ tender & 15 & 3.9 & 48 & 49.5 & 6 & 9.5 & $<0.001$ \\
\hline Guarding/rebound tenderness & 255 & 66.8 & 34 & 35.1 & 13 & 20.6 & $<0.001$ \\
\hline Hematocrit (\%) & $(\mathrm{n}=336)$ & & $(\mathrm{n}=86)$ & & $(\mathrm{n}=55)$ & & \\
\hline Mean (SD) & 38.0 & $(3.9)$ & 33.3 & $(6.0)$ & 36.5 & $(5.9)$ & $<0.001 *$ \\
\hline $\mathrm{WBC}\left(/ \mathrm{mm}^{3}\right)$ & $(\mathrm{n}=292)$ & & $(\mathrm{n}=71)$ & & $(\mathrm{n}=53)$ & & \\
\hline$\geq 10,000$ & 245 & 83.9 & 42 & 59.2 & 19 & 35.9 & \\
\hline Mean (SD) & $14,204.5$ & $(4,638.4)$ & $11,875.9$ & $(4,531.9)$ & $9,958.8$ & $(5,200.0)$ & $<0.001 *$ \\
\hline Neutrophil (\%) & $(\mathrm{n}=281)$ & & $(n=69)$ & & $(\mathrm{n}=51)$ & & \\
\hline$\geq 75$ & 171 & 60.9 & 39 & 56.5 & 10 & 19.6 & $<0.001$ \\
\hline Pregnancy & 7 & 1.8 & 47 & 48.5 & 3 & 4.8 & $<0.001$ \\
\hline
\end{tabular}

${ }^{*}$ Kruskal-Wallis equality-of-populations rank test. 
tions and medical specialties are not widely available. Diagnostic procedures, using combination of clinical findings and routine laboratories as diagnostic indicators, is probably more cost-effective and safe.

\section{Patients and Methods}

\section{Patients}

Patients were women aged 15 to 50 years who admitted to the surgical department or obstetrics and gynecological department in a tertiary care hospital during January to December 2008 with a chief compliant of acute lower abdominal pain within 14 days. The patients were eventually diagnosed with one of these conditions, appendicitis, common obstetrics and gynecological conditions (complicated ovarian cyst, PID, or ectopic pregnancy), or non-specific abdominal pain conditions (NSAP).

\section{Study variables}

Study variables are patients' baseline data (age and marital status), history of abdominal pain including duration of pain, shifting of pain from peri-umbilical area to right lower quadrant. Associated gastro-intestinal symptoms (anorexia, nausea, vomiting, and diarrhea), and gynecological conditions or symptoms (pregnancy and abnormal vaginal bleeding at time of admission) were recorded. Physical examination findings including body temperatures above 37.5 degree Celsius, systolic blood pressure, pulse rate, sites of tenderness, and signs of peritoneum irritation (guarding and rebound tenderness) were noted. Laboratory results from completed blood count and urine pregnancy test were also recorded.

\section{Data source and bias}

We used data from medical record reviews. Patients with readmission were excluded to reduce miss-classification bias. To minimize missing data of clinical signs and symptoms, medical records without notes on these variables are recorded as 'negative' for such signs and symptoms. Data were recorded in electronic case record forms.

\section{Statistical analysis}

Descriptive statistics (percentages, means, and standard deviations) were used for describing data. To test for differences among the three diagnostic categories, we used exact probability tests for categorical data, one-way ANOVA and Kruskal-Wallis equality-of-populations rank test for continuous data as appropriated. We applied the concept of regression model for likelihood ratios of positive test $(\mathrm{LR}+)$ [10] by using polytomous logistic regression to identify signifi- cant diagnostic indicators. Results were reported in LR+ and $95 \%$ confidence interval $(\mathrm{CI})$.

\section{Results}

Medical records of five hundred sixty three (563) patients were reviewed. Twenty one (21) patients were excluded because their chief complaints were not acute lower abdominal pain. Of the 542 patients remaining for analysis, appendicitis was the final diagnosis in 382 patients, obstetrics and gynecological (OB-GYN) conditions in 97 patients, and non-specific abdominal pain (NSAP) in 63 patients. For OB-GYN group, ectopic pregnancies were diagnosed in 48 patients, complicated ovarian cysts in 42 patients, and PID in 7 patients.

Age, marital status, and duration of pain were not different $(\mathrm{P}=0.937,0.943$, and 0.413$)$. Shifting of abdominal pain was observed more often in appendicitis $(31.3 \%)$ than in OB-GYN $(6.2 \%)$ and in NSAP $(17.5 \%, \mathrm{P}<0.001)$. Gastrointestinal symptoms such as anorexia, nausea and vomiting, were less observed in OB-GYN. The proportion of diarrhea in NSAP was higher (31.8\%) comparing to OB-GYN (4.1\%) and appendicitis $(7.6 \%, \mathrm{P}=0.002)$ (Table 1$)$.

Low-grade fever was found in $33.3 \%$ of appendicitis patients, $14.6 \%$ of OB-GYN, and $19.4 \%$ of NSAP $(\mathrm{P}<0.001)$. There were twelve OB-GYN patients (12.4\%) presented with hypotension. Left lower quadrant tenderness was predominated in OB-GYN patients $(49.5 \%, 3.9 \%$ in appendicitis, and $9.5 \%$ in NSAP, $\mathrm{P}<0.001)$. Right lower quadrant tenderness was reported in almost every appendicitis patient (97.9\%), and in high proportions of OB-GYN (73.2\%), and of NSAP $(84.1 \%, \mathrm{P}<0.001)$. Similarly, guarding and rebound tenderness was found more often in appendicitis (Table 1).

Leucocytosis (defined as white blood cell count $\geq$ $10,000 / \mathrm{mm}^{3}$ ) was found in $83.9 \%$ of appendicitis, $59.2 \%$ of OB-GYN, and $35.9 \%$ of NSAP $(\mathrm{P}<0.001)$. Percentage of neutrophil $\geq 75 \%$ was less observed in NSAP $(19.6 \%$, $60.9 \%$ in appendicitis, and $56.5 \%$ in OB-GYN, $\mathrm{P}<0.001$ ). Pregnancy was associated more often with OB-GYN group (Table 1).

\section{Multivariable analysis}

We analyzed all diagnostic indicators simultaneously, using the concepts of regression model for likelihood ratio of positive test, with polytomous logistic regression, to determine the effect of each indicator on the likelihood of each of the three diagnostic categories. Diagnostic indicators that increase the likelihood of appendicitis were: right lower quadrant tenderness, guarding and rebound tenderness, and leucocytosis. Left lower quadrant tenderness, pregnancy reduced likelihood of appendicitis. Indicators that increase likelihood of OB-GYN were: left lower quadrant tenderness, neutrophil 
Table 2. Likelihood Ratio of Positive Test $(\mathrm{LR}+)$ of Diagnostic Indicators From Multivariable Analysis

\begin{tabular}{|c|c|c|c|c|c|c|}
\hline \multirow{2}{*}{ Indicators } & \multicolumn{2}{|l|}{ Appendicitis } & \multicolumn{2}{|c|}{$\begin{array}{l}\text { Obstetric-gynecological } \\
\text { conditions }\end{array}$} & \multicolumn{2}{|c|}{$\begin{array}{l}\text { Non-specific abdominal } \\
\text { pain }\end{array}$} \\
\hline & $\begin{array}{l}\text { LR+ } \\
(95 \% C I)\end{array}$ & $\mathbf{P}$ & $\mathrm{LR}+(95 \% \mathrm{CI})$ & $\mathbf{P}$ & $\mathrm{LR}+(95 \% \mathrm{CI})$ & $\mathbf{P}$ \\
\hline Age $>25 y r$ & $\begin{array}{l}1.07 \\
(0.91-1.26)\end{array}$ & 0.395 & $\begin{array}{l}1.09 \\
(0.68-1.76)\end{array}$ & 0.711 & $\begin{array}{l}0.71 \\
(0.33-1.53)\end{array}$ & 0.379 \\
\hline Single & $\begin{array}{l}0.95 \\
(0.80-1.12)\end{array}$ & 0.542 & $\begin{array}{l}1.34 \\
(0.84-2.14)\end{array}$ & 0.216 & $\begin{array}{l}1.06 \\
(0.49-2.30)\end{array}$ & 0.884 \\
\hline Duration of pain $>24 \mathrm{hr}$ & $\begin{array}{l}1.11 \\
(0.94-1.31)\end{array}$ & 0.237 & $\begin{array}{l}0.86 \\
(0.51-1.44)\end{array}$ & 0.567 & $\begin{array}{l}0.89 \\
(0.50-1.57)\end{array}$ & 0.677 \\
\hline Shifting of pain & $\begin{array}{l}1.13 \\
(0.99-1.28)\end{array}$ & 0.068 & $\begin{array}{l}0.36 \\
(0.13-0.99)\end{array}$ & 0.047 & $\begin{array}{l}0.76 \\
(0.35-1.68)\end{array}$ & 0.501 \\
\hline Anorexia & $\begin{array}{l}0.98 \\
(0.81-1.17)\end{array}$ & 0.792 & $\begin{array}{l}0.34 \\
(0.13-0.88)\end{array}$ & 0.027 & $\begin{array}{l}1.66 \\
(0.69-4.00)\end{array}$ & 0.258 \\
\hline Nausea and vomiting & $\begin{array}{l}1.06 \\
(0.93-1.19)\end{array}$ & 0.375 & $\begin{array}{l}0.42 \\
(0.23-0.76)\end{array}$ & 0.004 & $\begin{array}{l}0.90 \\
(0.50-1.63)\end{array}$ & 0.728 \\
\hline $\begin{array}{l}\text { Abnormal vaginal } \\
\text { bleeding }\end{array}$ & $\begin{array}{l}0.23 \\
(0.03-1.51)\end{array}$ & 0.125 & $\begin{array}{l}1.15 \\
(0.56-2.39)\end{array}$ & 0.701 & $\begin{array}{l}0.24 \\
(0.03-2.30)\end{array}$ & 0.217 \\
\hline Diarrhea & $\begin{array}{l}0.84 \\
(0.63-1.10)\end{array}$ & 0.207 & $\begin{array}{l}0.85 \\
(0.32-2.25)\end{array}$ & 0.738 & $\begin{array}{l}2.93 \\
(1.55-5.56)\end{array}$ & 0.001 \\
\hline Temperature $\geq 37.5^{\circ} \mathrm{C}$ & $\begin{array}{l}1.00 \\
(0.88-1.14)\end{array}$ & 0.955 & $\begin{array}{l}0.71 \\
(0.38-1.33)\end{array}$ & 0.282 & $\begin{array}{l}1.06 \\
(0.54-2.06)\end{array}$ & 0.863 \\
\hline Tachycardia & $\begin{array}{l}0.95 \\
(0.83-1.09)\end{array}$ & 0.441 & $\begin{array}{l}1.05 \\
(0.61-1.81)\end{array}$ & 0.852 & $\begin{array}{l}1.22 \\
(0.62-2.43)\end{array}$ & 0.565 \\
\hline Systolic BP $\leq 90 \mathrm{mmHg}$ & $\begin{array}{l}0.88 \\
(0.33-2.31)\end{array}$ & 0.792 & $\begin{array}{l}2.08 \\
(0.82-5.29)\end{array}$ & 0.124 & $\begin{array}{l}0.78 \\
(0.10-6.07)\end{array}$ & 0.816 \\
\hline RLQ tender & $\begin{array}{l}2.30 \\
(1.17-4.51)\end{array}$ & 0.016 & $\begin{array}{l}0.53 \\
(0.31-0.93)\end{array}$ & 0.026 & $\begin{array}{l}0.75 \\
(0.31-1.82)\end{array}$ & 0.528 \\
\hline LLQ tender & $\begin{array}{l}0.22 \\
(0.10-0.48)\end{array}$ & $<0.001$ & $\begin{array}{l}3.59 \\
(2.27-5.66)\end{array}$ & $<0.001$ & $\begin{array}{l}0.79 \\
(0.30-2.13)\end{array}$ & 0.647 \\
\hline $\begin{array}{l}\text { Guarding/rebound } \\
\text { tenderness }\end{array}$ & $\begin{array}{l}1.25 \\
(1.10-1.43)\end{array}$ & 0.001 & $\begin{array}{l}0.69 \\
(0.42-1.12)\end{array}$ & 0.131 & $\begin{array}{l}0.37 \\
(0.19-0.71)\end{array}$ & 0.003 \\
\hline Hematocrit $<33 \%$ & $\begin{array}{l}0.84 \\
(0.65-1.09)\end{array}$ & 0.190 & $\begin{array}{l}1.61 \\
(0.87-2.98)\end{array}$ & 0.126 & $\begin{array}{l}0.98 \\
(0.43-2.23)\end{array}$ & 0.960 \\
\hline $\mathrm{WBC} \geq 10,000 / \mathrm{mm}^{3}$ & $\begin{array}{l}1.74 \\
(1.38-2.20)\end{array}$ & $<0.001$ & $\begin{array}{l}0.38 \\
(0.20-0.74)\end{array}$ & 0.004 & $\begin{array}{l}0.36 \\
(0.20-0.67)\end{array}$ & 0.001 \\
\hline Neutrophil $\geq 75 \%$ & $\begin{array}{l}1.00 \\
(0.88-1.15)\end{array}$ & 0.956 & $\begin{array}{l}1.96 \\
(1.11-3.45)\end{array}$ & 0.021 & $\begin{array}{l}0.33 \\
(0.16-0.66)\end{array}$ & 0.002 \\
\hline Pregnancy & $\begin{array}{l}0.31 \\
(0.14-0.69)\end{array}$ & 0.004 & $\begin{array}{l}2.24 \\
(1.18-4.25)\end{array}$ & 0.014 & $\begin{array}{l}1.18 \\
(0.32-4.29)\end{array}$ & 0.806 \\
\hline
\end{tabular}


Table 3. Summarized Direction of Likelihood of Diagnosis (Appendicitis, Common Obstetric and Gynecological Conditions; OB-GYN, or Non-Specific Abdominal Pain; NSAP) for Each Clinical Indicators

\begin{tabular}{llll}
\hline & & & \\
& & & \\
Diagnostic indicators & Appendicitis & OB-GYN & NSAP \\
\cline { 2 - 3 } & & Decrease & \\
Anorexia & & Decrease & \\
Nausea/vomit & & Decrease & \\
Shifting of pain & & Increase \\
Diarrhea & & Decrease & \\
RLQ tender & Increase & Increase & \\
LLQ tender & Decrease & & Decrease \\
Guarding $/$ rebound tenderness & Increase & Increase & \\
Pregnancy & Decrease & Decrease & Decrease \\
WBC $\geq 10,000 / \mathrm{mm}^{2}$ & Increase & Increase & Decrease \\
Neutrophil $\geq 75 \%$ & & & \\
\hline
\end{tabular}

$\geq 75 \%$, and pregnancy. Shifting of abdominal pain, anorexia, nausea and vomiting, right lower quadrant tenderness, and leucocytosis decreased likelihood of OB-GYN. Diarrhea increased likelihood of NSAP, while guarding and rebound tenderness, leucocytosis, and neutrophil $\geq 75 \%$ reduced likelihood of NSAP (Table 2, 3).

\section{Discussion}

Diagnosis of acute lower abdominal pain in a young adult woman is sometimes a challenging clinical situation. Both appendicitis and obstetrics and gynecological conditions need emergency management; therefore, timely and precision of diagnosis is warranted. Studies showed that CT, especially, spiral CT had higher accuracy in diagnosis of appendicitis than ultrasound $[11,12]$. In addition, CT scan resulted in changes of diagnosis in 6-36\% of acute lower abdominal pain patients [13]. Ultrasound still has its role in pregnant patients because of no radiation exposure [4].

Cost-effectiveness of CT is controversial. In one study, CT showed a reduction of cost in reproductive women with right lower abdominal pain by reducing the cost of unnecessary appendectomy [14]. However, the cost-effectiveness of $\mathrm{CT}$ is questionable when health re-imbursement scheme is global budgeting. Selective use of CT, therefore, was advised $[15,16]$.

Clinical scoring scheme is another approach to diagnosis of appendicitis. Alvarado's scoring scheme was developed for discriminate appendicitis from other causes of abdomi- nal pain [17]. Recently, it was applied for admission criteria rather than as a diagnostic tool [18].

One limitation of clinical scoring schemes for diagnosis of acute lower abdominal pain in reproductive women is that they were designed for diagnosis of single disease. When more than one diagnosis is the outcomes of interest in diagnostic studies, polytomous logistic regression may be applied $[19,20]$. In the present study, obstetrics and gynecological conditions were also common causes among these patients and urgent treatments for such conditions were important. The rationale of data analysis in the present study was to study the effect of clinical diagnostic indicators for appendicitis and OB-GYN simultaneously with NSAP. Therefore, polytomous logistic regression was used.

In multivariable polytomous logistic regression for likelihood ratio of positive test, anorexia, nausea and vomiting were associated with decreased likelihood of diagnosis OBGYN. Anorexia, nausea and vomiting are symptoms associated with gastrointestinal system while OB-GYN is associated with uro-genital system. Signs of peritoneal irritation such as guarding and rebound tenderness, when presented, were associated with decreased likelihood of NSAP.

Effects of clinical indicators that were summarized in Table 3 can be applied in selective approach to women at reproductive age who presented with acute lower abdominal pain. Patients with right lower quadrant tenderness, guarding and rebound tenderness, complete blood counts show leucocytosis and neutrophil more than $75 \%$, but are not pregnant and have no tenderness on left lower quadrant are likely to be appendicitis. General surgeons should be consulted to man- 
age these cases. Patients without gastro-intestinal symptoms (anorexia, nausea and vomit), no shifting of abdominal pain, no tenderness on right lower quadrant, no leucocytosis, but present with pregnancy and left lower quadrant tenderness are likely to be OB-GYN conditions. They should be managed by gynecologists. Patients who do not have signs of peritoneal irritation (guarding and rebound tenderness), no leucocytosis and present with diarrhea are possibly NSAP. They can be observed and periodically evaluated for progression of abdominal pain.

\section{Conclusion}

Clinical diagnostic indicators that may help differentiate appendicitis, OB-GYN conditions, and NSAP in acute lower abdominal pain in reproductive women are: anorexia, nausea and vomiting, shifting of abdominal pain, diarrhea, site of tenderness, guarding and rebound tenderness, pregnancy, leucocytosis, and neutrophil over $75 \%$.

\section{Conflict of Interest}

The authors declared none.

\section{References}

1. Kruszka PS, Kruszka SJ. Evaluation of acute pelvic pain in women. Am Fam Physician. 2010;82(2):141-147.

2. Brown T, Herbert ME. Medical myth: Bimanual pelvic examination is a reliable decision aid in the investigation of acute abdominal pain or vaginal bleeding. CJEM. 2003;5(2):120-122.

3. Ackerman SJ, Irshad A, Anis M. Ultrasound for pelvic pain II: nongynecologic causes. Obstet Gynecol Clin North Am. 2011;38(1):69-83, viii.

4. Chen MM, Coakley FV, Kaimal A, Laros RK, Jr. Guidelines for computed tomography and magnetic resonance imaging use during pregnancy and lactation. Obstet Gynecol. 2008;112(2 Pt 1):333-340.

5. Cicchiello LA, Hamper UM, Scoutt LM. Ultrasound evaluation of gynecologic causes of pelvic pain. Obstet Gynecol Clin North Am. 2011;38(1):85-114, viii.

6. Gjelsteen AC, Ching BH, Meyermann MW, Prager DA, Murphy TF, Berkey BD, Mitchell LA. CT, MRI, PET, PET/CT, and ultrasound in the evaluation of obstetric and gynecologic patients. Surg Clin North Am. 2008;88(2):361-390, vii.

7. Masselli G, Brunelli R, Casciani E, Polettini E, Bertini L, Laghi F, Anceschi M, et al. Acute abdominal and pel- vic pain in pregnancy: MR imaging as a valuable adjunct to ultrasound? Abdom Imaging. 2011;36(5):596-603.

8. Gaitan H, Angel E, Sanchez J, Gomez I, Sanchez L, Agudelo C. Laparoscopic diagnosis of acute lower abdominal pain in women of reproductive age. Int J Gynaecol Obstet. 2002;76(2):149-158.

9. Wen SW, Naylor CD. Diagnostic accuracy and shortterm surgical outcomes in cases of suspected acute appendicitis. CMAJ. 1995;152(10):1617-1626.

10. Leisenring W, Pepe MS. Regression modelling of diagnostic likelihood ratios for the evaluation of medical diagnostic tests. Biometrics. 1998;54(2):444-452.

11. Paulson EK, Kalady MF, Pappas TN. Clinical practice. Suspected appendicitis. N Engl J Med. 2003;348(3):236242.

12. Balthazar EJ, Birnbaum BA, Yee J, Megibow AJ, Roshkow J, Gray C. Acute appendicitis: CT and US correlation in 100 patients. Radiology. 1994;190(1):31-35.

13. Neumayer L, Kennedy A. Imaging in appendicitis: a review with special emphasis on the treatment of women. Obstet Gynecol. 2003;102(6):1404-1409.

14. Morse BC, Roettger RH, Kalbaugh CA, Blackhurst DW, Hines WB, Jr. Abdominal CT scanning in reproductiveage women with right lower quadrant abdominal pain: does its use reduce negative appendectomy rates and healthcare costs? Am Surg. 2007;73(6):580-584; discussion 584.

15. Morris KT, Kavanagh M, Hansen $\mathrm{P}$, Whiteford $\mathrm{MH}$, Deveney K, Standage B. The rational use of computed tomography scans in the diagnosis of appendicitis. Am J Surg. 2002;183(5):547-550.

16. Lin KH, Leung WS, Wang CP, Chen WK. Cost analysis of management in acute appendicitis with CT scanning under a hospital global budgeting scheme. Emerg Med J. 2008;25(3):149-152.

17. Alvarado A. A practical score for the early diagnosis of acute appendicitis. Ann Emerg Med. 1986;15(5):557564.

18. Chan MY, Tan C, Chiu MT, Ng YY. Alvarado score: an admission criterion in patients with right iliac fossa pain. Surgeon. 2003;1(1):39-41.

19. Biesheuvel CJ, Vergouwe Y, Steyerberg EW, Grobbee DE, Moons KG. Polytomous logistic regression analysis could be applied more often in diagnostic research. J Clin Epidemiol. 2008;61(2):125-134.

20. Van Calster B, Valentin L, Van Holsbeke C, Testa AC, Bourne T, Van Huffel S, Timmerman D. Polytomous diagnosis of ovarian tumors as benign, borderline, primary invasive or metastatic: development and validation of standard and kernel-based risk prediction models. BMC Med Res Methodol. 2010;10:96. 